\title{
Brachydactyly mental retardation syndrome with growth hormone deficiency
}

\author{
Alireza Arefzadeh', Pooyan Khalighinejad2, Bahar Ataeinia ${ }^{3}$ and Pegah Parvar4 \\ ${ }^{1}$ Endocrinology Department, School of Medicine, Shahid Beheshti University of Medical Sciences, Tehran, Iran, ${ }^{2 S c h o o}$ \\ of Medicine, Isfahan University of Medical Sciences, Isfahan, Iran, ${ }^{35}$ chool of Medicine, Tehran University of Medical \\ Sciences, Tehran, Iran, and ${ }^{4}$ School of Medicine, Islamic Azad University Medical Branch of Tehran, Tehran, Iran
}

\author{
Correspondence \\ should be addressed \\ to A Arefzadeh \\ Email \\ alireza.arefzadeh@gmail. \\ com
}

\section{Summary}

Deletion of chromosome 2 q37 results in a rare congenital syndrome known as brachydactyly mental retardation (BDMR) syndrome; a syndrome which has phenotypes similar to Albright hereditary osteodystrophy (AHO) syndrome. In this report, we describe a patient with AHO due to microdeletion in long arm of chromosome 2 [del(2) (q37.3)] who had growth hormone (GH) deficiency, which is a unique feature among reported BDMR cases. This case was presented with shortening of the fourth and fifth metacarpals which along with AHO phenotype, brings pseudopseudohypoparathyroidism (PPHP) and pseudohypoparathyroidism type la (PHP-la) to mind; however, a genetic study revealed del(2)(q37.3). We recommend clinicians to take BDMR in consideration when they are faced with the features of AHO; although this syndrome is a rare disease, it should be ruled out while diagnosing PPHP or PHP-la. Moreover, we recommend evaluation of IGF 1 level and GH stimulation test in patients with BDMR whose height is below the 3rd percentile.

\section{Learning points:}

- Clinicians must have brachydactyly mental retardation (BDMR) syndrome in consideration when they are faced with the features of Albright hereditary osteodystrophy.

- Although BDMR syndrome is a rare disease, it should be ruled out while diagnosing PPHP or PHP-la.

- Evaluation of IGF1 level in patients diagnosed with BDMR whose height is below the 3rd percentile is important.

\section{Background}

Deletion of chromosome $2 \mathrm{q} 37$ results in a rare congenital syndrome known as brachydactyly mental retardation (BDMR) syndrome (1), which presents with obesity, round face, short stature, brachydactyly type E (BDE), congenital heart defects, autism and other intellectual disabilities, mildto-moderate mental retardation syndrome, developmental defects and seizures (2). These symptoms are similar to Albright hereditary osteodystrophy (AHO) syndrome (3).

Shortening of the fourth and fifth metacarpals is seen in various disorders in addition to BDMR; common etiologies are pseudopseudohypoparathyroidism (PPHP), pseudohypoparathyroidism type Ia (PHP-Ia), Turner syndrome and post-infection complications (e.g. osteomyelitis) $(4,5)$. Since PHP-Ia and PPHP have AHO phenotype (6), they are important differentials of BDMR syndrome.

In this case report, we describe a patient with AHO phenotype due to microdeletion in long arm of chromosome 2[del(2)(q37.3)] who had growth hormone deficiency. 


\section{Case presentation}

An 8-year-old girl of Iranian ethnicity was presented to us with obesity and severe short stature, with her height of $107.5 \mathrm{~cm}$ being 4.0 s.D. below the mean. Her important physical examination findings were obesity $(\mathrm{BMI}=29.2)$, mild mental retardation, autistic features, round face, highly arched eyebrows, depressed nasal bridge, hypotonia, joint hypermobility and short fourth and fifth metacarpal and metatarsal fingers (Fig. 1).

She was born at 38th week of gestation, with a spontaneous and uncomplicated delivery. After 2 years, her parents noticed her mental retardation and autismlike features. No other points in her past medical history seemed to be of importance. Father's and mother's height were $186 \mathrm{~cm}$ and $169 \mathrm{~cm}$ respectively.

During the examinations, the patient was not cooperative with the examining physician and showed aggressive behaviors. Her thyroid was normal in size, texture, consistency and without palpable mass. Puberty staging was normal in breast, axillary and pubis at stage 1 of Tanner scale. No more abnormal findings were observed in her examinations, other than the earlier mentioned ones.
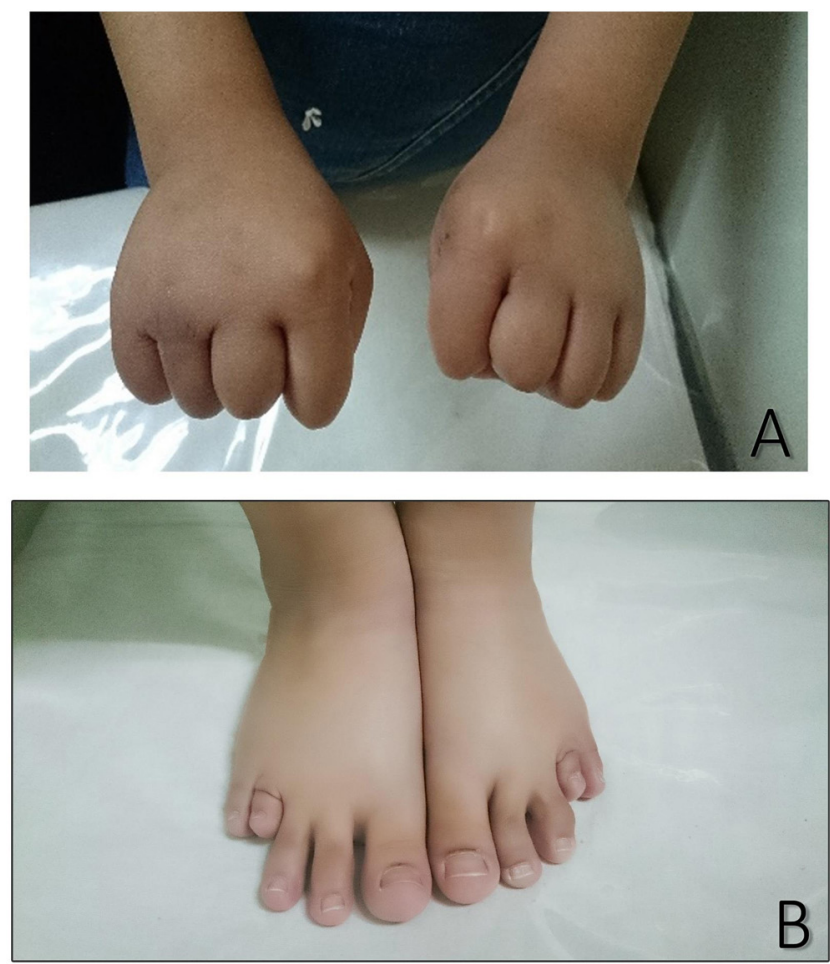

Figure 1

Apparent shortening of 4th and 5th metacarpals and metatarsals in patient's hands (A) and feet $(B)$, respectively.
Blood panel tests were performed and findings are summarized in Table 1, of which the most important data were IGF-I value was $22 \mathrm{ng} / \mathrm{mL}$ lower than the normal age-sex specific reference ranges: $(39-396 \mathrm{ng} / \mathrm{mL}$, S.D. score $=-3.14)$. The low IGF-1 was important result in screening for GHD. A clonidine test was performed to confirm GH deficiency with a peak GH of only $1.3 \mathrm{ng} / \mathrm{mL}$.

Plain radiographic studies of the hands and feet showed fourth and fifth metacarpal and metatarsal shortening, and bone age of 8 years (Fig. 2).

Table 1 Patient's blood panel.

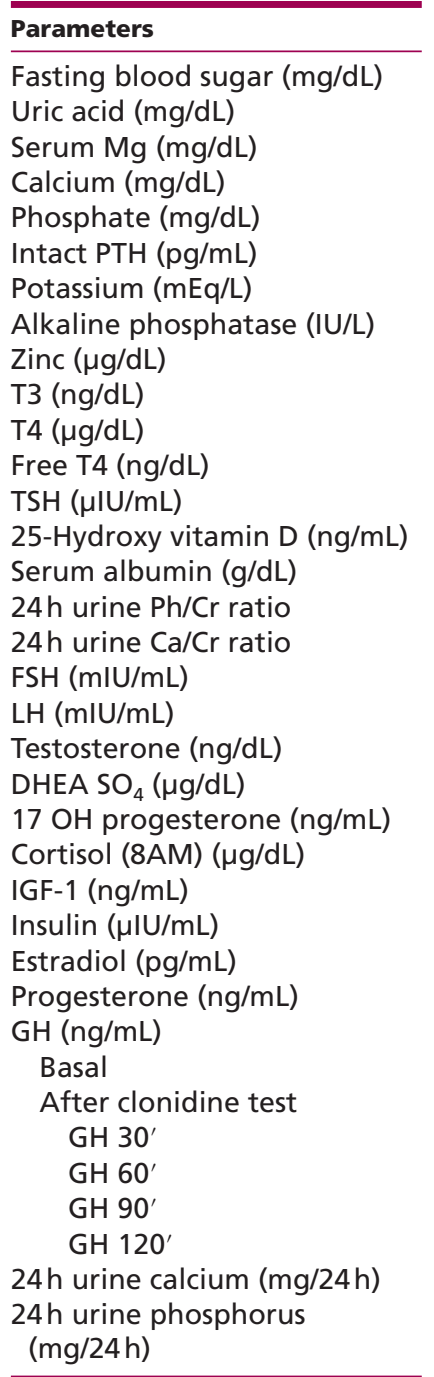

\begin{tabular}{|c|c|}
\hline Value & Normal range \\
\hline 76.2 & $80-100$ \\
\hline 5.1 & $3-6.4$ \\
\hline 2.9 & $1.6-3$ \\
\hline 9.6 & 8.4-10.4 \\
\hline 4.7 & $3.2-5.4$ \\
\hline 44.30 & $15-65$ \\
\hline 4.6 & $3.5-5.1$ \\
\hline 352 & $180-1200$ \\
\hline 90 & 70-100 \\
\hline 197 & $80-230$ \\
\hline 11.5 & $4.6-12$ \\
\hline 1.15 & $0.7-1.9$ \\
\hline 1.030 & $0.3-3.5$ \\
\hline 36.4 & $30-100$ ** \\
\hline 4.2 & $3.5-5.3$ \\
\hline 0.97 & $0.153-1.44$ \\
\hline 0.07 & $\leq 0.2$ \\
\hline 0.2 & $2.8-11.3$ \\
\hline 0.1 & $1.1-11$ \\
\hline 5.0 & $<7-20$ \\
\hline 79.1 & 44-332 \\
\hline 0.439 & $<2.5$ \\
\hline 5.539 & 4-25 \\
\hline 22 & $39-396^{+}$ \\
\hline 10 & $1.4-14$ \\
\hline 5.9 & $0.1-160$ \\
\hline 0.3 & $0.15-1.4$ \\
\hline 0.5 & $0.01-4$ \\
\hline $0.2 *$ & \\
\hline $1.3^{*}$ & \\
\hline $1.2 *$ & \\
\hline $0.6 *$ & \\
\hline 56 & $50-300$ \\
\hline 399 & $385-1300$ \\
\hline
\end{tabular}

*Deficiency: (A normal response following stimulation tests is a peak $\mathrm{GH}$ concentration $>5 \mathrm{ng} / \mathrm{mL}$ in children and $>4 \mathrm{ng} / \mathrm{mL}$ in adults. For children, some experts consider $\mathrm{GH}$ values between $5 \mathrm{ng} / \mathrm{mL}$ and $8 \mathrm{ng} / \mathrm{mL}$ equivocal and only $\mathrm{GH}$ peak values $>8 \mathrm{ng} / \mathrm{mL}$ as truly normal); **sufficient range; ${ }^{t}$ normal age-sex specific ranges. 


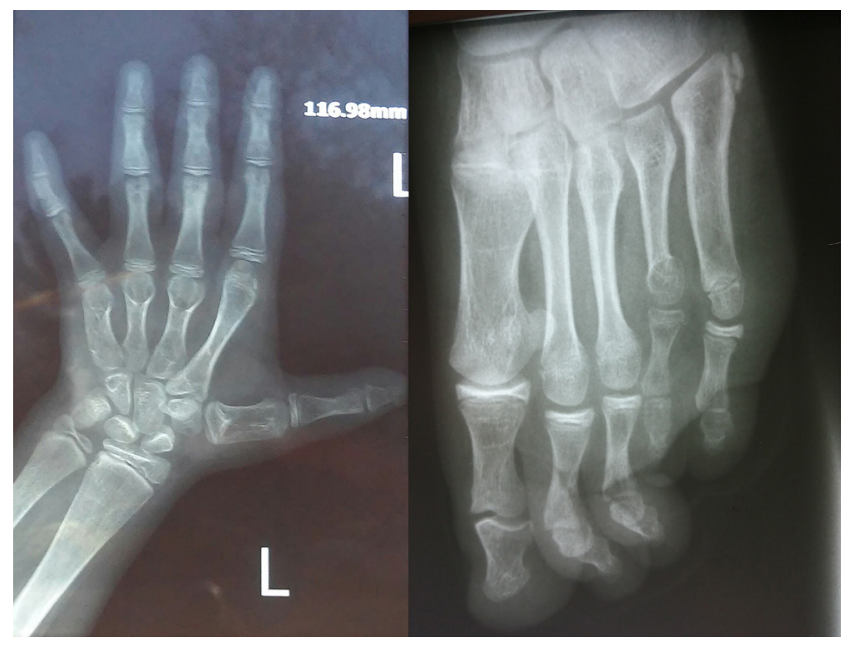

Figure 2

Plain radiograph studies of left foot and hand.

\section{Investigations}

The patient had AHO phenotype, however, she had normal serum levels of calcium, phosphorus and parathyroid hormone; this scenario is commonly seen in PPHP. Shortening of the fourth and fifth metacarpals is seen in Turner syndrome. The patient did not have any past histories of trauma or infection of her feet and hands; therefore, post infectious complications were ruled out. Genetic studies were performed to rule out PPHP and Turner syndrome.

\section{Karyotype and conventional cytogenetic study}

Fifteen metaphase spreads from the patient were analyzed with a high-resolution 500-550 GTG banding according to standard procedures using a lithium-heparin peripheral blood sample. The test showed deletion in long arm of chromosome 2, which was occurred in all spreads [46,XX,del(2)(q37.3)]. Karyotype was 46XX and Turner syndrome was ruled out.

\section{Fluorescence in situ hybridization}

A fluorescence in situ hybridization (FISH) analysis was performed on metaphase chromosomes from peripheral blood lymphocytes. The slides were prepared according to standard cytogenetic procedures. Double-colored FISH probes including Tel 2q (Spectrum Red) and CEP 17 (Spectrum Green) as control probes, using probe direct labeled fluorescent Vysis DNA probe kit (Abbott Molecular) were applied. Thirty interphasic and metaphasic cells were screened. The result of GTG banding was approved.
Deletion (2)(q37.3) was detected and the analysis showed 46,XX,del(2)(q37.3).ish del(2)(q37.3q37.3)(DS244-)[15]. nuc ish(DS2447x1)[15].

Patient's parents did not have any clinical manifestations of BDMR syndrome or PPHP and genetic studies were performed on them, which did not reveal PPHP or BDMR syndrome.

\section{Interventions and follow-up}

Since the patient had GH deficiency as well as a short stature, she was treated with biosynthetic growth hormone (Pen Nordilet $5 \mathrm{mg} / 1.5 \mathrm{CC}$ ) approximately with a dosage of $0.6 \mathrm{mg} /$ day or $4.2 \mathrm{mg} /$ weekly. Her growth velocity improved after 2 years. The patient's height increased to $122.5 \mathrm{~cm}$ (near $3 \mathrm{rd}$ percentile), and $140 \mathrm{~cm}$ (above the 50th percentile), respectively, 1 year and 2 years after GH therapy. The patient's weight increased from $33.8 \mathrm{~kg}$ before treatment to $41 \mathrm{~kg}$ and $49 \mathrm{~kg}$, respectively, 1 year and 2 years after GH therapy. The patient's BMI decreased from 29.2 before treatment to 27.32 and 25 , respectively, 1 year and 2 years after GH therapy. The chart of height and weight is demonstrated in Fig. 3.

She was referred to the psychology and speech therapy departments for treatment of behavioral and speech disorders. She was also referred to the cardiology department to assess probable cardiovascular complications; no abnormalities were found in her cardiovascular evaluation. New hormone panel tests were performed which did not show gonadal axis activity or an increase in sexual hormones; and her staging of puberty was within normal range.

\section{Discussion}

Deletions of 2q37 have been described clinically with obesity, overweight, moon face, short stature, intellectual deficiency and brachydactyly, resembling AHO syndrome; however, some features are present in this syndrome which are different from AHO, such as congenital hypotonia, cardiovascular disorders, mildto-severe developmental delays, mental retardation, facial prominent foreheads, frontal bossing, a flat nasal bridge, small or large ears, down turned-corners of the mouth, highly arched eyebrows, depressed nasal bridge, prominent ear helix, epicanthic folds, palpebral fissure slant up, highly arched eyebrows, deep-set eyes, a thin upper lip, prominent lower lip, strabismus, gaze palsy, sparse hair and alopecia areata $(7,8,9)$. Bone deformities such as brachymetaphalangism, asymmetrical legs and 
2 to 20 years: Girls

Stature-for-age and Weight-for-age percentiles
NAME

RECORD \#

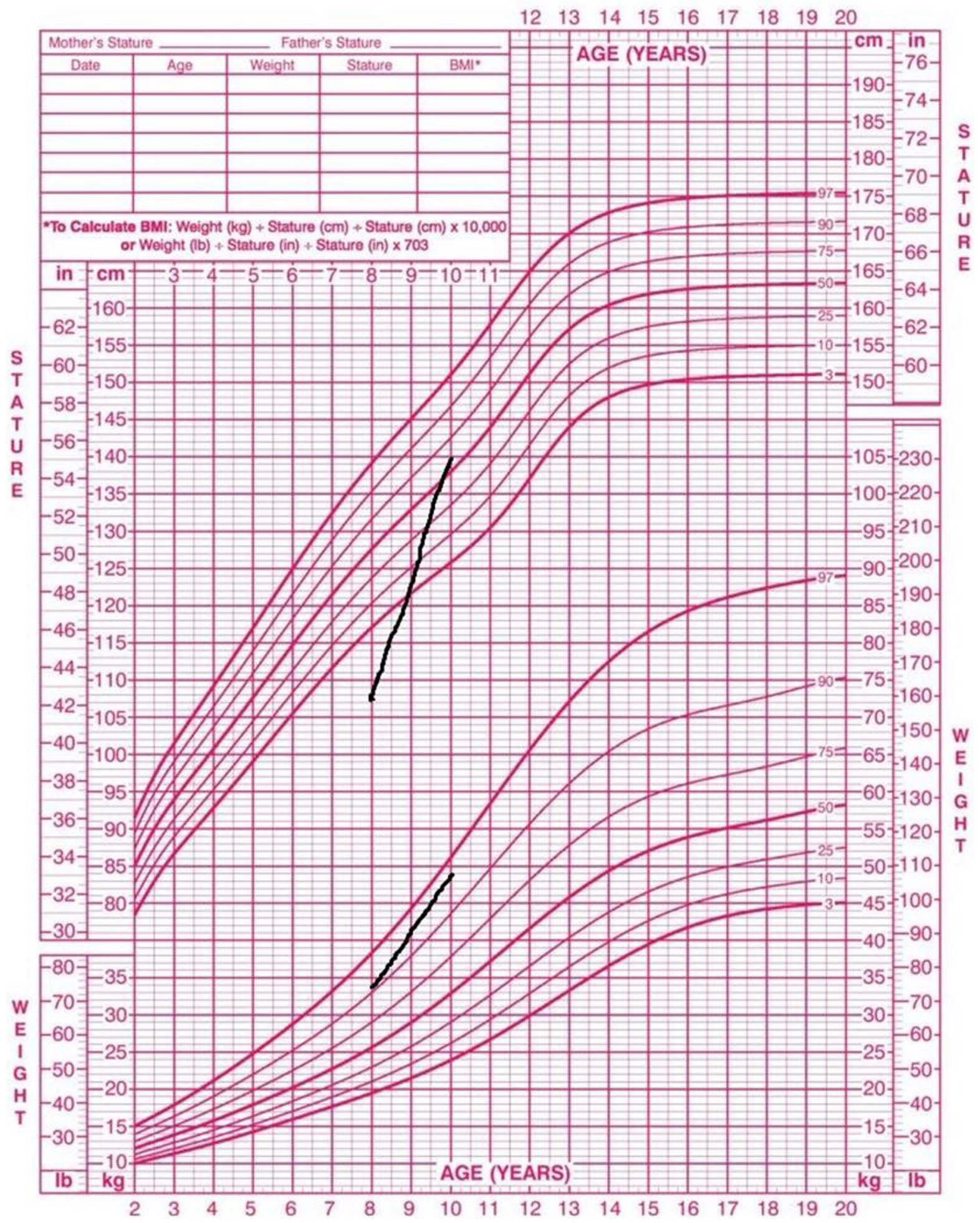

Figure 3

Growth and weight chart. 
broad halluces have also been described (8). A study by Casas et al. (13) showed that more than $40 \%$ of patients were obese or overweight and obesity was seen more commonly in the elderly and subjects with large deletions (13). Hydrocephalus, microcephaly, dilated ventricles and seizures have also been reported in BDMR (14).

Alanine glyoxylate aminotransferase (AGXT) gene, is located on chromosome 2q37; and its deletion in BDMR leads to excess excretion of oxalate or primary hyperoxaluria type 1 , which results in accumulation of calcium oxalate in the kidney and leads to progressive loss of renal function (15). HDAC4 haploinsufficiency causes psychomotor and behavioral disorders such as self-injuries, aggressive behavior, autistic disorders and developmental delay (16).

\section{Paternal or maternal imprinting}

Most patients with the 2q37 microdeletion have a de novo chromosome deletion and their parents have normal karyotypes (17). Leroy et al. showed that the deletion of $2 \mathrm{q} 37$ region was of maternal origin whereas the $2 \mathrm{q}$ polymorphism was found in the father (8). In a case series by Leroy et al., a paternal origin of the $2 \mathrm{q} 37$ deletion was seen in five patients and a maternal origin was seen in four (8). Deletion or mutation of HDAC4 may be inherited in an autosomal dominant manner but is more commonly de novo $(14,16)$.

PHP-Ia and PPHP patients compared to BDMR, have mutations in the GNAS1 gene located on chromosome 20q13.11, which encodes adenylate-cyclase-stimulating G-alpha-protein causing both syndromes to develop AHO syndrome's phenotype. PHP-Ia is caused due to maternal imprinting, while PPHP is caused due to paternal imprinting of the mutation (10).

\section{Risk of cancer}

Sakai et al. have reported a 2-year-old boy with BDMR, who developed a sex cord-stromal tumor at 3 months of age. Their study showed that haploinsufficiency of the genes at $2 \mathrm{q} 37$, rather than segmental duplications of $1 \mathrm{p} 36$ or $20 \mathrm{p} 12$, has dominant effects on phenotype presentation (18). Drake et al. studied a series of sporadic Wilms tumors and found evidence of a tumor suppressor role for a $360-\mathrm{kb}$ critical region at $2 \mathrm{q} 37$ encompassing the DIS3 mitotic control homolog (Saccharomyces cerevisiae)like 2 (DIS3L2) locus. Their study showed that loss of heterozygosity at $2 \mathrm{q} 37$ was in at least $4 \%$ of population with sporadic Wilms' tumors (19).

\section{BDMR with GH deficiency}

GH deficiency has been reported in PPHP and PHP-I patients before (20); however, it is not common in BDMR. Cho et al. have reported the patient with BDMR, growth retardation and partial GH deficiency that responded well to GH therapy (21). Kitsiou-Tzeli et al. have described a 13-year-old girl with BDMR and GH deficiency and compensate hypothyroidism (22). To date, there have been only three reports of GH deficiency in patients with $\operatorname{BDMR}(21,22,23)$.

Clinicians generally have good knowledge about AHO syndrome; nonetheless, BDMR is a rare genetic disorder that practitioners do not usually face in routine practice. Thus, some BDMR patients may get referred to endocrinologists and get mistakenly diagnosed with PPHP or PHP-Ia. PHP-Ia patients have loss-of-function mutations of the GNAS1 gene, which leads to inability of adenyl cyclase activation when PTH binds to its receptor. However, PPHP patients have normal serum calcium concentrations and no renal tubular resistance to PTH (10).

On the other hand, BDMR patients have normal calcium, phosphorus and parathyroid hormone levels, which result in the characteristic osteodystrophy with normal renal response to the parathyroid hormone and preserved calcium homeostasis. These patients have normal urinary CAMP response to PTH and normal urinary $\mathrm{PO} 4$ response to $\mathrm{PTH}$, as observed in our case $(4,11)$. Shortening of the fourth and fifth metacarpals and metatarsals (brachymetaphalangism) is typically seen in both PPHP and BDMR patients (12).

\section{Management and treatment}

Multidisciplinary approach including genetic study, speech therapy, physical therapy, child development, cardiology, neurology, gastroenterology, nutrition/ feeding, ophthalmology and audiology disorders are recommended in BDMR patients (14).

Periodic routine primary care and reevaluation by a medical geneticist, periodic management of behavioral and cognitive problems, screening for renal cysts at age of 4 and at puberty are suggested. Moreover, screening for Wilms tumor should be considered in young cases (14).

Clinicians should consider BDMR syndrome in differential diagnosis of patients with AHO phenotype especially when calcium, phosphorous and PTH are normal (PPHP) $(3,11)$.

We suggest clinicians screen for GH deficiency with an IGF-1 level in patients with BDMR, whose height is 
below the 3rd percentile. Although this deficiency has been reported in PPHP and PHP-I patients before (20). To date, there have been only three reports of GH deficiency in patients with $\operatorname{BDMR}(21,22,23)$. Further studies are required to determine the prevalence and also the etiology of this phenomenon.

\section{Conclusions}

We recommend clinicians to take brachydactyly mental retardation syndrome in consideration when they are faced with the features of $\mathrm{AHO}$; although this syndrome is a rare disease, it should be ruled out while diagnosing PPHP or PHP-Ia. Moreover, we recommend evaluation of IGF1 level in patients diagnosed with BDMR whose height is below than 3rd percentile.

\section{Declaration of interest}

The authors declare that there is no conflict of interest that could be perceived as prejudicing the impartiality of the research reported.

\section{Funding}

This research did not receive any specific grant from any funding agency in the public, commercial or not-for-profit sector.

\section{Patient consent}

A written signed informed consent was obtained from the patient's parents for publication of the submitted article and accompanying images.

\section{Author contribution statement}

Pooyan Khalighinejad gathered the case's information and records and drafted the manuscript. Bahar Ataeinia and Pegah Parvar completed the manuscript drafting and finalized the manuscript. The whole process was under supervision and guidance of Alireza Arefzadeh. He also revised the final version of the manuscript. All the authors read and approved the final version before submission.

\section{Acknowledgment}

The authors would like to thank Dr Hossein Gharib for his great guidance.

\section{References}

1 Online Mendelian Inheritance in Man O. MIM Number: 600430. Baltimore, MD: Johns Hopkins University.

2 Williams SR, Aldred MA, Der Kaloustian VM, Halal F, Gowans G, McLeod DR, Zondag S, Toriello HV, Magenis RE \& Elsea SH. Haploinsufficiency of HDAC4 causes brachydactyly mental retardation syndrome, with brachydactyly type $\mathrm{E}$, developmental delays, and behavioral problems. American Journal of Human Genetics 201087 219-228. (https://doi.org/10.1016/j.ajhg.2010.07.011)
3 Hacıhamdioğlu B, Arslan M, Sarı E, Kurtçu K \& Yesilkaya E. Brachydactyly mental retardation syndrome in differential diagnosis of pseudopseudohypoparathyroidism. Journal of Pediatric Endocrinology and Metabolism 201326 793-795. (https://doi. org/10.1515/jpem-2012-0375)

4 Goswami M, Verma M, Singh A, Grewal H \& Kumar G. Albright hereditary osteodystrophy: a rare case report. Journal of Indian Society of Pedodontics and Preventive Dentistry 200927 184. (https://doi. org/10.4103/0970-4388.57101)

5 Reeder MM, Bradley WGJ \& Merritt CR. Reeder and Felson's Gamuts in Radiology: Comprehensive Lists of Roentgen Differential Diagnosis. New York: Springer, 2003.

6 Mantovani G. Clinical review: pseudohypoparathyroidism: diagnosis and treatment. Journal of Clinical Endocrinology and Metabolism 2011 96 3020-3030. (https://doi.org/10.1210/jc.2011-1048)

7 Chromosome 2q37 Deletion: Clinical and Molecular Aspects. Proceedings of the American Journal of Medical Genetics Part C: Seminars in Medical Genetics, pp 357-371. Wiley Online Library.

8 Leroy C, Landais E, Briault S, David A, Tassy O, Gruchy N, Delobel B, Grégoire MJ, Leheup B, Taine L, et al. The 2q37-deletion syndrome: an update of the clinical spectrum including overweight, brachydactyly and behavioural features in 14 new patients. European Journal of Human Genetics 201321 602-612. (https://doi.org/10.1038/ ejhg.2012.230)

9 Williams SR, Aldred MA, Der Kaloustian VM, Halal F, Gowans G, McLeod DR, Zondag S, Toriello HV, Magenis RE \& Elsea SH. Haploinsufficiency of HDAC4 causes brachydactyly mental retardation syndrome, with brachydactyly type E, developmental delays, and behavioral problems. American Journal of Human Genetics 201087 219-228. (https://doi.org/10.1016/j.ajhg.2010.07.011)

10 Thiele S, Werner R, Grotzinger J, Brix B, Staedt P, Struve D, Reiz B, Farida J \& Hiort O. A positive genotype-phenotype correlation in a large cohort of patients with pseudohypoparathyroidism type Ia and pseudo-pseudohypoparathyroidism and 33 newly identified mutations in the GNAS gene. Molecular Genetics and Genomic Medicine 20153 111-120. (https://doi.org/10.1002/mgg3.117)

11 Mehraein Y, Pfob M, Steinlein O, Aichinger E, Eggert M, Bubendorff V, Mannhart A \& Müller S. 2q37.3 deletion syndrome: two cases with highly distinctive facial phenotype, discordant association with schizophrenic psychosis, and shared deletion breakpoint region on 2q37.3. Cytogenetic and Genome Research 2015 146 33-38. (https://doi.org/10.1159/000431389)

12 Aldred M, Sanford R \& Thomas N. Molecular analysis of 20 patients with 2q37.3 monosomy: definition of minimum deletion intervals for key phenotypes. Journal of Medical Genetics 200441 433-439. (https://doi.org/10.1136/jmg.2003.017202)

13 Casas KA, Mononen TK, Mikail CN, Hassed SJ, Li S, Mulvihill JJ, Lin HJ \& Falk RE Chromosome 2q terminal deletion:report of 6 new patients and review of phenotype-breakpoint correlations in 66 individuals. American Journal of Medical Genetics Part A 2004 130A 331-339. (https://doi.org/10.1002/ajmg.a.30156)

14 Doherty ES \& Lacbawan FL. 2q37 Microdeletion Syndrome, 2013.

15 Tammachote R, Kingsuwannapong N, Tongkobpetch S, Srichomthong C, Yeetong P, Kingwatanakul P, Monico CG, Suphapeetiporn K \& Shotelersuk V. Primary hyperoxaluria type 1 and brachydactyly mental retardation syndrome caused by a novel mutation in AGXT and a terminal deletion of chromosome 2. American Journal of Medical Genetics Part A 2012158 2124-2130. (https://doi.org/10.1002/ajmg.a.35495)

16 Villavicencio-Lorini P, Klopocki E, Trimborn M, Koll R, Mundlos S \& Horn D. Phenotypic variant of brachydactyly-mental retardation syndrome in a family with an inherited interstitial 2q37.3 microdeletion including HDAC4. European Journal of Human Genetics 201321 743-748. (https://doi.org/10.1038/ejhg.2012.240)

17 Ravnan JB, Tepperberg JH, Papenhausen P, Lamb AN, Hedrick J, Eash D, Ledbetter DH \& Martin CL. Subtelomere FISH analysis 
of 11688 cases: an evaluation of the frequency and pattern of subtelomere rearrangements in individuals with developmental disabilities. Journal of Medical Genetics 200643 478-489. (https://doi. org/10.1136/jmg.2005.036350)

18 Sakai Y, Souzaki R, Yamamoto H, Matsushita Y, Nagata H, Ishizaki Y, Torisu H, Oda Y, Taguchi T, Shaw CA, et al. Testicular sex cordstromal tumor in a boy with $2 \mathrm{q} 37$ deletion syndrome. BMC Medical Genomics 20147 19. (https://doi.org/10.1186/1755-8794-7-19)

19 Drake KM, Ruteshouser EC, Natrajan R, Harbor P, Wegert J, Gessler M, Pritchard-Jones K, Grundy P, Dome J, Huff V, et al. Loss of heterozygosity at 2q37 in sporadic Wilms' tumor: putative role for miR-562. Clinical Cancer Research 200915 5985-5992. (https://doi. org/10.1158/1078-0432.CCR-09-1065)

20 Mantovani G, Ferrante E, Giavoli C, Linglart A, Cappa M, Cisternino M, Maghnie M, Ghizzoni L, de Sanctis L, Lania AG, et al. Recombinant human GH replacement therapy in children with pseudohypoparathyroidism type Ia: first study on the effect on growth. Journal of Clinical Endocrinology and Metabolism 201095 5011-5017. (https://doi.org/10.1210/jc.2010-1649)

21 Cho EK, Kim J, Yang A, Cho SY \& Jin DK. 2q37 deletion syndrome confirmed by high-resolution cytogenetic analysis. Annals of Pediatric Endocrinology and Metabolism 201722 129-132. (https://doi. org/10.6065/apem.2017.22.2.129)

22 Kitsiou-Tzeli S, Sismani C, Ioannides M, Bashiardes S, Ketoni A, Touliatou V, Kolialexi A, Mavrou A, Kanavakis E \& Patsalis PC. Array-CGH analysis and clinical description of 2 q37.3 de novo subtelomeric deletion. European Journal of Medical Genetics 200750 73-78. (https://doi.org/10.1016/j. ejmg.2006.09.004)

23 Wilson LC, Leverton K, Oude Luttikhuis ME, Oley CA, Flint J, Wolstenholme J, Duckett DP, Barrow MA, Leonard JV, Read AP, et al. Brachydactyly and mental retardation: an Albright hereditary osteodystrophy-like syndrome localized to 2q37. American Journal of Human Genetics 199556 400-407.

Received in final form 21 May 2018

Accepted 14 June 2018 